\title{
A novel architecture to monetize digital offerings
}

\author{
Richard Reisman $^{1} \cdot$ Marco Bertini $^{2}$
}

Received: 5 September 2017/ Accepted: 6 February 2018/Published online: 26 February 2018

(C) The Author(s) 2018. This article is an open access publication

\begin{abstract}
As commerce continues to shift to the digital domain, organizations respond by improving and evolving their approach to creating value for customers. When the time comes to convert digital anything into cash they can bank, the same organizations, however, seem stuck in time. The purpose of the article is to highlight this inconsistency and, importantly, propose a solution. First, we leverage the literature on freemium and participative pricing mechanisms to lay the foundations for a revenue architecture fit for the digital economy. We argue in favor of three building blocks: empowerment, dialog, and reputation. Second, we describe FairPay as a promising configuration of these factors.
\end{abstract}

Keywords Pricing - Electronic commerce - Revenue models $\cdot$ Digital goods $\cdot$ Price discrimination

The shift of commerce to the digital domain has forced many organizations to rethink their approach to turning customer value into revenue, at times even backtracking to the very question of what "value" actually means to those they strive to serve. Electronic commerce often plays by different, new rules, yet the way companies convert digital anything into cash they can bank seems stuck in time,

Richard Reisman

rreisman@teleshuttle.com

Marco Bertini

marco.bertini@esade.edu

1 Teleshuttle Corporation, 20 East 9th Street, New York, NY 10003, USA

2 ESADE-Ramon Llull University, Avinguda de la Torre Blanca 59, 08172 Sant Cugat Del Vallès, Spain obeying rules and practices that may have made sense for physical goods but make far less sense today. ${ }^{1}$

Some visionaries spotted this inconsistency and claim that "free" and, in particular, the popular hybrid "freemium" are clever ways to turn lemons into lemonade. The idea is to leverage the absence of a price in the short term, for a bare bones version of the offering, or for a select group of customers to gather a critical mass of users who later convert into faithful payers (Anderson 2009). Indeed, the rapid growth of on-demand access, not to mention the bleak outlook for revenue from digital advertising, continues to inspire businesses to market innovative models of subscription or membership that leverage the intuitive appeal of freemium.

If one can replicate digital goods at little to no cost, then what can possibly be the harm? We can think of at least two problems. First, the prospect of giving stuff away today in the hope of a hefty payday tomorrow is inherently risky, as finding the mix of free and fee that achieves growth without stifling profitability is far from simple (Berman 2011; Kumar 2014). Second, the power of digitization to deliver infinite variety suggests that squeezing every need, want, and consumption pattern into one or a few rigid prices is inefficient. To be sure, some players, especially the undisputed leaders in a market, fare reasonably well. However, many (most?) others face a deepening crisis: even recognized success stories such as The

\footnotetext{
1 The newspaper industry is a good example of just how difficult it can be to thrive when business goes digital, especially when the establishment is chronically resistant to change. David Carr, at The New York Times, summarized the industry's precarious position as follows: "Producing serious news is an expensive enterprise with a beleaguered business model, one that remains tied to the tracks as a locomotive of splintered audiences and declining advertising hurtles toward it" (The New York Times; October 20, 2013).
} 
New York Times, Netflix, and Spotify are probably leaving good money on the table or foregoing sales that would still be profitable at some lower price.

We believe that earning revenue in the digital age needs a fresh approach. Recently, we have noticed organizations that use crowdfunding platforms or bet on rather extreme mechanisms such as "pay-what-you-want" and voluntary memberships. But can we do better? We think so, and use this article to lay the foundations. In particular, we present a revenue architecture that aims to move the exchange between company and customer from the confrontational, impersonal, and transactional to the collaborative, personal, and relational. Critically, we want to nudge the conversation away from price to value-for-money by championing three building blocks: empowerment, dialog, and reputation.

The hope is that businesspeople embrace our recommendations and mold them to fit their unique goals and contexts. The key to success is realizing that price is not an end in itself, but an instrument to balance perceptions of value and fairness in an ongoing relationship. Early experience and ingenuity will certainly dictate which specific configurations of our general architecture prove most successful. To kick-start the debate, we introduce FairPay as one promising alternative.

\section{Three building blocks}

Throughout most of the history of commerce, price was the outcome of a barter, haggle, or negotiation between sellers and buyers, typically in the context of an ongoing relationship. Different buyers achieved different prices depending on their current situation, needs, and bargaining power. In other words, prices were participative and personal.

However, starting in around the 1850s, the shift to mass retail shoved this protocol to the side. Shoppers no longer purchased from individuals, but from organizations preoccupied by economic efficiency. The company dictated terms, with prices set to achieve some financial objective and offered to the whole market on a take-it-or-leave-it basis. Indeed, the price tag gained popularity in those years with the arrival of the department store. John Wanamaker, the trailblazing, deeply religious American merchant owner of a department store by the same name opined, "If everyone is equal before God, then everyone should also be equal before price." Prices became imposed and impersonal.

Today's technologies make it possible to achieve personalization and dialog at scale, yet businesses are stuck in the "arm's length" logic that they set prices and the market accepts or rejects them. Businesses may appreciate that prices should mirror the individual situations of customers (as they once did), and indeed dynamic pricing is a booming field, but there is no real consensus on how to make this happen in a way that is palatable to customers.

Our suggestion seeks to reap the economic benefit of price discrimination while retaining the efficiency inherent to institutionalized commerce. The goal is to create an environment where company and customer explore different pricing rationales over time, searching for a balance that both sides perceive as fair. To achieve this, we emphasize three building blocks (for a similar rationale, see Bertini and Gourville 2012).

\section{Empowerment}

Companies are embracing the idea of delegating activities to customers. We see it in product development and advertising, among others. But what about pricing? After all, the "right" price from a company's perspective is contingent on the value perceived by the buyer. Moreover, asking customers to participate in pricing decisions is empowering, and empowerment is known to foster engagement and satisfaction (for more on the relationship between pricing and engagement, see Bertini and Wathieu 2010).

Customer participation of course need not be an all-ornothing proposition, as different pricing mechanisms involve customers to different extents (Bertini and Koenigsberg 2014; Spann et al. 2018). Irrespective, consider for a second the extreme case of pay-what-you-want, which has gained a foothold in some commercial contexts. Intuition suggests that letting customers dictate prices is foolhardy, practical only as a cute promotional stunt. Indeed, the thought of yielding any pricing power is often frightening to managers. However, a growing body of academic research and business experience shows that the selling context can be managed creatively to prime customers to pay fairly - even generously (Kim et al. 2009; Natter and Kaufmann 2015). Few customers take a purely self-interested economic perspective on exchanges. Rather, people are often driven by social values and norms (of fairness, reciprocity, altruism, etc.), they respond to trust and transparency and to different styles of communication, and they can be swayed by how choices are presented to them-all of which can drive cooperation (Santana and Morwitz 2014).

\section{Dialog}

Tapping the market for insight and feedback is sound, intuitive advice. But how often does a company work to create a true dialog with its customers? In addition, even if there is a structure in place to communicate, how often does this structure inform the challenging task of putting a 
price on value? The ideal pricing process is one where there is (plenty of) learning, one where the company gradually discovers what each customer (or, at least, different customer segment) values and why, and in return, the customer perceives a willingness from the company to reciprocate with increasingly tailored offerings.

Modern e-commerce platforms can enable this sort of rich, automated, and personalized discussion. The technology is there, but it is currently underused. Two good examples are customer relationship management and social media systems, typically employed to manage interactions and build loyalty, not to engage customers into meaningful conversations. Our suggestion is that pricing processes formalize and integrate dialogs about all things of valueneeds, wants, features, services, pain points, price levels, current and future transactions, etc. As a result, prices become emergent and better attuned to dynamic and complex market environments (Smith 2012). This kind of cooperation in pricing has been labeled "co-pricing" in existing conceptual work (Frow et al. 2015). We propose a practical form of this concept.

\section{Reputation}

Relationships depend on reputation. Customer participation in pricing needs to be counterbalanced by feedback about results-a control mechanism for the company to decide when and how much discretion to grant. That is, the customer's power to set prices cannot be absolute; it must depend explicitly on her behavior. We propose to anchor this feedback control on perceptions of fairness, as the overall objective is to focus both parties to an exchange on the need for outcomes that are mutually beneficial.

From the perspective of the business, a "fair" customer is probably one who is sufficiently profitable over the length of the relationship. Instituting a "fairness rating" for each customer, one that updates automatically over time, enables companies to manage the allocation of pricing discretion. This suggestion is a logical extension of the more familiar rating systems we see in reward programs, sharing services, credit scoring, and the like. One resulting application is to put customers who repeatedly price unfairly on "warning," and eventually even to revoke their pricing privilege. Similarly, the fairness rating serves to reward customers who price generously (with additional features, premium product offers, etc.). Meanwhile, a "fair" business from the perspective of the customer is probably one that provides sufficient value for money over the length of the relationship, one that is transparent and trustworthy, and one that is open and responsive to meaningful dialogs.

\section{Fairpay}

FairPay is one vision, our vision, of how these building blocks combine in practice to shift commerce from isolated transactions to cooperative exchange relations. This is how it works.

\section{Empowerment}

Here, we take what may appear an extreme view: customers experience the product or service and then set the price unilaterally. However, we also make the privilege revocable. That is, customers have the freedom to pay whatever they think is fair, including zero, but retaining it going forward is conditional on the company perceiving that the relationship is converging to a price level that is acceptable for that particular individual. A variety of reference points can be provided to help customers and anchor their decisions. One of these references can be the standard fixed price, which also serves as the fallback alternative when customers are excluded from participating in the price-setting process because of freeriding or ineligibility. (Indeed, the company may decide to limit the pay-whatyou-think-is-fair privilege to certain customer profiles.) This setup frames the exchange as a repeated game, in the hope of applying a certain balance of power between buyer and seller across iterations (Greiff and Egbert 2016).

Note the sequencing of experience first, price later. The timing matters because it can be beneficial to take pricing risk off the shoulders of the customer (especially when the marginal cost of supplying the product or service is negligible). To the extent that digital goods are experience goods, this order eliminates the customer's tendency to discount for possible disappointment and signals trust, which fosters reciprocity-a strong social norm (Egbert et al. 2014).

\section{Dialog}

A dialog structure is applied and managed in pursuit of a fair and agreeable balance of power between business and customer. The company suggests and justifies a personalized price to guide the customer's decision. If the customer chooses a price that differs from this suggestion, she is encouraged to justify her decision (especially in the case of a reduction). This happens by means of simple choice templates, suited for automation and personalization. Moreover, we suggest that the company makes an attempt to prime generosity by providing supporting information (Kahneman et al. 1986). This may include-but is certainly not limited to-data on usage levels and patterns, costs, financial imperatives and objectives, social values 
supported by the company, and social benchmarks (a table listing typical payments, ranking relative standings, etc.). Ahead of the next transaction, the company recaps this evidence, as well as counterarguments as appropriate, to ensure that the conversation progresses.

At the same time, the customer has the power to adjust the price to pay, and give reasons for any such movement (a different perception of value, a change in the ability to pay, etc.). Over time, this dialog gains richness and nuance since each party to the exchange is free to raise whatever argument or metric of value appears relevant to the relationship. Instead of bargaining over the price at single point in time, the bargaining is over these arguments and the value of the relationship as it evolves.

The structured dialog within FairPay continues as long as the company accepts the customer's prices (in the context of the justifications that explain these prices) - a decision that is made by weighing the customer's fairness rating and other factors against the company's internal criteria for continuing to extend their privilege to set prices unilaterally.

\section{Reputation}

In FairPay, a customer's fairness rating combines four elements: (1) the difference between the personalized price suggested by the company and the price paid by the customer, (2) the customer's explanation(s) for this difference, (3) relevant details of the transaction (e.g., the quantity and nature of use by the customer), and (4) the customer's history. This information is updated at every purchase occasion and feeds into future suggested prices. Decisions can then be made at each customer-pricing cycle-extending rewards (additional product tiers, perks, etc.) to customers with excellent fairness ratings, and enforcing penalties (most strongly, the threat to remove the ability to set the price) to customers with poor fairness ratings.

Decision rules for each segment of customers can be as liberal or stringent as the company desires, granting more or less freedom. The business retains control of the interaction and can engineer it to optimize customer lifetime value (the total value received from that customer), profit, and market reach-and pricing risk. Balancing that on the side of customers is a shift in the focus of competition from price to perceptions of value received from the vendor, trust, and fairness.

At the broadest level, this architecture subsumes the traditional company-imposed fixed price as the lowestfreedom case and pay-what-you-want as the highest-freedom case. Within specific segments and instances, the rules can provide a new kind of "value discrimination" that considers usage levels and patterns, outcomes, and ability to pay, in a way that can be forgiving of lower-than- average prices by customers who realize relatively low value, while nudging toward higher prices those who realize greater value.

\section{Getting started}

FairPay is one of many possible applications of the principles outlined above. Yet we see it is a lightweight and, importantly, scalable process for setting the right price to each customer at each stage of the relationship. FairPay aims to reflect a customer's experience of value and find a fair split of the surplus created by the exchange.

Building the necessary infrastructure to support FairPay may seem daunting at first, but it is possible to start simple. For example, one way to incorporate the prices paid by a customer into her fairness rating is to track the percentage differentials from the company's suggested prices, as percentages can be compared easily and meaningfully across occurrences. These differentials can then be adjusted to account for that customer's justifications and relevant contextual factors, as described above (using simple rules and thresholds), to generate the overall fairness rating and decide on further offers in an adaptive way.

The type of dialog that we want companies to institute with their customers draws on and generates what today may be termed "big data." The data that comprise the customers' value assessments and reasons, and the corresponding fairness ratings, are critical for managing the pricing process itself and valuable in other aspects such as marketing and product design. Moreover, the fairness data gain value when aggregated across organizations. A company such as Amazon, or alternatively a payment processor, can aggregate fairness ratings across the merchants it serves and use the information much like credit scores help determine credit limits.

One doubt that comes to mind is whether customers can cope with the added cognitive load of participating in the process of setting a price. Here, it is important to note that motivating customers to think about value is not necessarily a bad thing (especially for a business that provides good value): there is considerable research in decision making showing that mental effort can stimulate the type of engagement that staves commoditization in a sector (Bertini and Wathieu 2010). Moreover, one can manage the demand placed on customers by paying attention to depth, frequency, and structure of the dialog. Again, it need not be an all-or-nothing proposition. The first interactions with a customer are likely to be the most challenging. With familiarity, however, the pricing process updates in larger and less-frequent batches, and with less effort. Before long, the company and customer agree to put this on "autopilot," applying negotiated pricing defaults that simplify the 
interaction. These can be revisited periodically or on demand. Designed properly, an interactive pricing architecture need not be more difficult for customers than deciding on a tip after a pleasant meal at a restaurant.

Notwithstanding, FairPay is new. Eager organizations need some time to apply it effectively. In fact, it is likely to work better at first with certain lines of business and certain segments of customers. That is, the learning curve may look different within a given organization. Managers attracted to our architecture need to tread cautiously in the interest of minimizing the cannibalization of existing revenue. With respect to lines of business, the low-hanging fruit lays where marginal costs are negligible, and the perception of value (and usage) by customers is generally high but sufficiently heterogeneous. A good starting point is to implement FairPay for focused tasks such as customer retention, upselling (to seek added revenue from premium services, features, etc.), and acquisition (to broaden the market without simply giving away the bottom tier). With respect to customer segments, it makes sense to start with those who are most disposed toward generosity or cooperation (the "super fans" who are loyal, perceive lots of value, and appreciate the "carrots" offered to them by the company).

\section{The invisible handshake?}

Adam Smith's famous metaphor of the "invisible hand" presumes that supply in a market is limited. Resources are scarce. Now consider a digital context where supply, in fact, is virtually limitless. Should the process of reaching a price change as a consequence? Can you expect customers to pay anything for something that is in boundless supply? The subscription economy points toward the answer: we agree to make recurring payments not only to obtain the current or latest products, but also to sustain a continuing supply - a social contract over a relationship. FairPay takes this logic a step further, in the form of a repeated, adaptive interaction that serves as an invisible "handshake," if you will. It is an agreement to cooperate: the firm gives its customers discretion over prices at each stage of the game, but this privilege can be revoked if certain minimum acceptable conditions are not met.

Importantly, this invisible handshake considers value on a far broader basis, and on a longer horizon, than the invisible hand. Why pressure businesses about social values and triple bottom lines? Because current bottom lines reflect only narrow and immediate aspects of value. But the invisible handshake can consider and operationalize all aspects of value that the customer and the business wish to consider. Prices can reflect not just traditional financial aspects, but social and environmental values. We can set the price to reflect the value of investigative journalism, cultural creation, innovation, design, style, and whatever other factors are raised as relevant. The price flows into the single bottom line (needing no extraneous bottom lines) and so directly into macroeconomic measures of productivity and GNP. People can begin to feel aligned with businesses, in a new kind of cooperative relationship-based capitalism. Loyalty loops can center on value. Customers can incentivize companies to produce value in whatever dimensions they seek (to the extent that they pay for it). This can apply to for-profits, as well as non-profits and cooperatives. Whatever the organization, we can move toward a richer and fuller digital wealth of nations that aligns better with human values and longer-term interests. Instead of the one-sided, zero-sum efficiency of price discrimination, we can seek cooperation to foster more value for both the business and society.

There has been ongoing controversy over the relative merits of the existing methods of value exchange: free versus fee in digital markets, value-based pricing more broadly, and the broader values of a market system. In our mind, the business case for advancing these debates lies in a company's willingness to realize that customers today are not the passive price takers of yesteryears. We propose a revenue architecture for the digital era that tries to marry this reality with pragmatic business needs. Finding the right balance will certainly require experimentation and adaptation, which may diverge from the specifics that we propose, but the essential direction seems sound: to create a more open, adaptive marketplace that lets sellers and buyers interact and learn about each other in lasting relationships seeking outcomes that are mutually satisfactory.

As with many aspects of the digital economy, there will be first mover advantages that create formidable barriers to entry - such as by achieving a level of price efficiency that improves both customer lifetime value and market reach, and by building a fairness reputation database that characterizes the value perceptions and pricing behaviors of large numbers of customers. Managed with care, the costs and risks of doing limited trials of an architecture such as FairPay are not large. The cost of allowing competitors to learn how to do this first, however, could be so.

Open Access This article is distributed under the terms of the Creative Commons Attribution 4.0 International License (http://crea tivecommons.org/licenses/by/4.0/), which permits unrestricted use, distribution, and reproduction in any medium, provided you give appropriate credit to the original author(s) and the source, provide a link to the Creative Commons license, and indicate if changes were made.

\section{References}

Anderson, Chris. 2009. Free: How Today's Smartest Businesses Profit by Giving Something for Nothing. New York: Hyperion. 
Berman, Saul J. 2011. Not for Free: Revenue Strategies for a New World. Cambridge: Harvard Business Review Press.

Bertini, Marco, and John T. Gourville. 2012. Pricing to Create Shared Value. Harvard Business Review 90 (6): 96-104.

Bertini, Luc Wathieu. 2010. How to Stop Customers from Fixating on Price. Harvard Business Review 88 (5): 84-91.

Bertini, Oded Koenigsberg. 2014. When Customers Help Set Prices. MIT Sloan Management Review 55 (4): 57-64.

Egbert, Henrik, Matthias Greiff, and Kreshnik Xhangolli. 2014. PWYW Pricing ex Post Consumption: A Sales Strategy for Experience Goods. Journal of Innovation Economics and Management 16 (1): 249-264.

Frow, Pennie, Richard Reisman, and Adrian Payne. 2015. "CoPricing: Co-Creating Customer Value through Dynamic Value Propositions", The 2015 Naples Forum on Service: Service Dominant Logic, Network and Systems Theory, and Service Science. Italy: Naples.

Greiff, Matthias, and Henrik Egbert. 2016. The Pay-What-You-Want Game: What Can be Learned from the Experimental evidence on Dictator and Trust Games? Management and Marketing 12 (1): 124-139.

Kahneman, Daniel, J.L. Knetsch, and Richard H. Thaler. 1986. Fairness as a Constraint on Profit Seeking: Entitlements in the Market. American Economic Review 76 (4): 728-741.

Kim, Ju-Young, Martin Natter, and Martin Spann. 2009. Pay What You Want: A New Participative Pricing Mechanism. Journal of Marketing 73 (1): 44-58.

Kumar, Vineet. 2014. Making 'Freemium' Work. Harvard Business Review 92 (5): 27-29.

Natter, Martin, and Katherina Kaufmann. 2015. Voluntary Market Payments: Underlying Motives, Success Drivers and Success Potentials. Journal of Behavioral and Experimental Economics 57 (C): 149-157.
Santana, Shelle Vicky, G. Morwitz. 2014. We're in This Together: How Social Values and Relationship Norms Influence Buyer Payments in Pay What You Want Settings. Harvard Business School working paper.

Smith, Gerald. 2012. Emergent Pricing Strategy. In Visionary Pricing: Reflections and Advances in Honor of Dan Nimer, ed. Gerald Smith, 103-128. Emerald Group: Bingley.

Spann, Martin, Robert Zeithammer, Marco Bertini, Ernan Haruvy, Sandy Jap, Oded Koenigsberg, Vincent Mak, Peter Popkowski Leszczyc, Bernd Skiera, and Manoj Thomas. 2018. Beyond Posted Prices: The Past, Present, and Future of Participative Pricing Mechanisms. Customer Needs and Solutions. https://doi. org/10.1007/s40547-017-0082-y.

Richard Reisman is the President and founder of Teleshuttle Corporation, and a successful inventor and entrepreneur with diverse experience in digital content industries. He manages and consults for corporations of all sizes, developed a variety of pioneering online services, and holds over 50 patents licensed by over 200 companies. His book, FairPay: Adaptively Win-Win Customer Relationships, and blog, FairPayZone.com, introduce a new revenue strategy for digital content and services.

Marco Bertini is an Associate Professor of Marketing at ESADERamon Llull University. His research appears in the leading journals for marketing science and practice. He was recently named to the Thinkers50 Radar, a shortlist of the scholars "most likely to shape the future of how organizations are managed and led." Prior to this, he was nominated for the Business Professor of the Year Award, a competition of the Economist Intelligence Unit, and recognized by the Marketing Science Institute as one of the most promising researchers in the field. 